\title{
Formation of Compact Myelin Is Required for Maturation of the Axonal Cytoskeleton
}

\author{
Scott T. Brady, ${ }^{1}$ Andrea S. Witt, ${ }^{1}$ Laura L. Kirkpatrick, ${ }^{2}$ Sylvie M. de Waegh, ${ }^{3}$ Carol Readhead, ${ }^{4}$ \\ Pang-Hsien Tu, ${ }^{5}$ and Virginia M.-Y. Lee ${ }^{5}$ \\ ${ }^{1}$ University of Texas Southwestern Medical Center, Department of Cell Biology and Neuroscience, Dallas, Texas \\ 75235-9039, '²Baylor College of Medicine, Department of Molecular and Human Genetics, Houston, Texas 77030, \\ ${ }^{3}$ University of Wisconsin, Madison, Wisconsin 53706, ${ }^{4}$ California Institute of Technology, Biological Imaging Center, \\ Pasadena, California 91125, and ${ }^{5}$ University of Pennsylvania School of Medicine, Pathology, and Laboratory Medicine, \\ Philade/phia, Pennsy/vania 19104-4283
}

\begin{abstract}
Although traditional roles ascribed to myelinating glial cells are structural and supportive, the importance of compact myelin for proper functioning of the nervous system can be inferred from mutations in myelin proteins and neuropathologies associated with loss of myelin. Myelinating Schwann cells are known to affect local properties of peripheral axons (de Waegh et al., 1992), but little is known about effects of oligodendrocytes on CNS axons. The shiverer mutant mouse has a deletion in the myelin basic protein gene that eliminates compact myelin in the CNS. In shiverer mice, both local axonal features like phosphorylation of cytoskeletal proteins and neuronal perikaryon functions like cytoskeletal gene expression are al-
\end{abstract}

The first description of non-neuronal cells in nervous tissue is generally attributed to Virchow (1846), when he described material that filled spaces between nerve elements. For much of the last century and a half, the operational definition of glia for many neuroscientists was not much more detailed. Although a substantial literature has accrued on glia (Kettenmann and Ransom, 1995), the roles of glia in the nervous system remain less well defined than those of neurons. Contemporary neuroscience texts list glial functions variously as providing structural support for neurons, formation of myelin sheaths for insulating large axons, buffering of ionic environment and clearance of neurotransmitters, and poorly defined nutritive activities. However, recent evidence suggests a wider range of glial activities affecting neuronal function. In particular, cell-cell communication between neurons and glia may be more extensive than previously thought. Given the intimate relationship between myelinating glia and their associated axons, the potential of myelin-forming glia to affect neuronal properties is considerable.

Analysis of axons in mice with mutations affecting myelination has proven particularly instructive. For example, Trembler mice are characterized by demyelination of large axons in the periph-

Received Oct. 2, 1998; revised June 11, 1999; accepted June 11, 1999.

This work was supported in part by National Institute of Neurological Disease and Stroke Grants NS23868 and NS23320 to S.T.B., a joint grant from NASA and the National Institute of Aging (NAG2-962/AG12646), the Welch Foundation (\#1237), and the Muscular Dystrophy Association. We thank Milena Gould, Enid Romanelli, and Martha Stokely for technical support. C.R. acknowledges Cedars-Sinai Medical Center for its support.

Correspondence should be addressed to Dr. Scott T. Brady, University of Texas Southwestern Medical Center, Department of Cell Biology And Neuroscience, 5323 Harry Hines Boulevard, Dallas, TX 75235-9039.

Copyright (c) 1999 Society for Neuroscience 0270-6474/99/197278-11\$05.00/0 tered. This leads to changes in the organization and composition of the axonal cytoskeleton in shiverer unmyelinated axons relative to age-matched wild-type myelinated fibers, although connectivity and patterns of neuronal activity are comparable. Remarkably, transgenic shiverer mice with thin myelin sheaths display an intermediate phenotype indicating that CNS neurons are sensitive to myelin sheath thickness. These results indicate that formation of a normal compact myelin sheath is required for normal maturation of the neuronal cytoskeleton in large CNS neurons.

Key words: myelin; cytoskeleton; neurofilaments; oligodendrocytes; slow axonal transport; phosphorylation eral nervous system (PNS) (Low and McLeod, 1975) with no significant effect on myelination of CNS axons. Trembler is a dominant mutation with several alleles, all associated with alterations in a peripheral myelin protein, PMP22 (Suter et al., 1992a,b). PMP22 is also defective in Charcot-Marie-Tooth type IA peripheral neuropathy (Lupski et al., 1991), making Trembler a homolog of the human disease. Affected PNS axons undergo continuing cycles of myelination and demyelination, resulting in a high percentage of large axons with little or no compact myelin (Low, 1976a,b).

Studies on Trembler mouse nerves revealed significant changes in large peripheral axons associated with demyelination. Both organization and dynamics of the axonal cytoskeleton in PNS nerves were altered by demyelination. Remarkably, most changes were restricted to axon segments without compact myelin (Aguayo et al., 1977; de Waegh et al., 1992). Local alterations in axons included rates of slow axonal transport (de Waegh and Brady, 1990; de Waegh et al., 1992), phosphorylation of neurofilament and microtubule protein (de Waegh et al., 1992; Kirkpatrick and Brady, 1994), and neurofilament density (de Waegh and Brady, 1991; de Waegh et al., 1992). Subsequent studies on normal myelinated fibers and other models of PNS hypomyelination confirmed that myelination locally influences neurofilament density and phosphorylation (Mata et al., 1992; Cole et al., 1994; Hsieh et al., 1994). Gaps in myelin as small as a PNS node of Ranvier produce dramatic, highly localized changes in axon cytoskeletal organization (de Waegh, 1990; Mata et al., 1992; Hsieh et al., 1994) and neurofilament phosphorylation (Mata et al., 1992; Hsieh et al., 1994). This led to the proposal that myelinating glia play a primary role in regulation of axon cytoskeletal orga- 
nization and targeting of axonal proteins like sodium channels (de Waegh et al., 1992; Brady, 1993).

Demyelination-induced changes in PNS axons raised questions about effects of myelination on CNS axons. CNS myelin is produced by oligodendrocytes rather than Schwann cells, and some functions served by Schwann cells in the PNS may be filled by astrocytes in the CNS. The protein composition (Morell et al., 1994) and fine structure (Raine, 1984; Peters et al., 1991) of CNS myelin differ from PNS myelin. Because central myelination is unperturbed in Trembler, we analyzed a different mouse mutant. Shiverer is a recessive mutation with a more severe phenotype than Trembler. Shiverer mutant mice not only develop a severe tremor in early postnatal development, but they have a mean life span of $\sim 100 \mathrm{~d}$ (Chernoff, 1981). Shiverer mice lack compact CNS myelin (Readhead and Hood, 1990) because of deletion of coding regions in the myelin basic protein (MBP) gene (Roach et al., 1985), a major structural protein of CNS myelin (Campagnoni and Macklin, 1988). Although MBP is expressed in PNS myelin as well, two PNS-specific proteins, $\mathrm{P}_{0}$ and $\mathrm{P}_{2}$, appear to have functional overlap with MBP so PNS myelination is near normal (Rosenbluth, 1980).

Unlike Trembler where PNS axons are subject to a constant cycle of myelination and demyelination, the absence of a major structural protein for myelin means that shiverer CNS axons never see normal myelin. Studies with various mouse strains indicate that MBP expression can limit myelin sheath formation (Shine et al., 1992), and transgenic mice expressing intermediate levels of MBP in a shiverer background (Readhead et al., 1987) have been generated. Mice homozygous for the MBP transgene express only $25 \%$ of wild-type MBP levels resulting in thin compact myelin with few lamellae. However, this is sufficient to suppress tremors and increase life spans to near wild-type, effecting a "cure" of this neurogenetic disease (Readhead et al., 1987). Availability of shiverer (shi) and transgenic mice homozygous for the MBP transgene (MBP/MBP) permitted evaluation of compact myelin effects on CNS neurons.

A wide range of neuronal parameters were altered in shiverer mouse CNS tissues. These included differences in slow axonal transport, cytoskeletal composition, posttranslational modification of cytoskeletal proteins, axon caliber, and neuronal gene expression. In each case, neurons in the shiverer mouse exhibited characteristics similar to early postnatal axons before myelination. Remarkably, analysis of these same parameters in the CNS of MBP/MBP mice with minimal tremor and normal life spans revealed a phenotype with features of both wild-type and shiverer. Rates of slow axonal transport and levels of NFM neurofilament protein in axons were comparable to wild-type in MBP/ MBP mice, whereas other aspects of the axonal cytoskeleton and neuronal gene expression in $\mathrm{MBP} / \mathrm{MBP}$ mice were more like shiverer.

These results demonstrate that myelinating glia in the CNS profoundly influence associated neurons and suggest an extensive dialogue between oligodendrocytes and axons. Myelinating glia influence both local axonal features like posttranslational modification of cytoskeletal proteins as well as cytoskeletal gene expression in the neuronal perikaryon. Incomplete recovery of normal phenotype in neurons of $\mathrm{MBP} / \mathrm{MBP}$ mice implies that multiple regulatory pathways exist, which are somehow modulated by the amount of compact myelin. Taken together, these results indicate that formation of compact myelin is required for maturation of the neuronal cytoskeleton in large neurons of the CNS.

\section{MATERIALS AND METHODS}

All chemicals used were American Chemical Society quality or better and were obtained from Sigma (St. Louis, MO), Calbiochem (La Jolla, CA), or Polysciences (Warrington, PA). Shiverer and MBP/MBP Shiverer transgenic mice (Male and female, 4-6 weeks old, from the colony maintained by Carol Readhead, Cedars Sinai Medical Center, Los Angeles, CA) were used for all experiments. Age-matched wild-type mice (B6C3/F1) were obtained from The Jackson Laboratory (Bar Harbor, ME). Because shiverer mice are not hardy, all mice were housed in a sterile environment and were fed sterile food and water throughout the experiments.

Axonal transport labeling and analysis. Proteins in axonal transport were labeled in mouse optic nerve by intravitreal injection of $0.5 \mathrm{mCi}\left[{ }^{35} \mathrm{~S}\right] \mathrm{me}-$ thionine (Trans ${ }^{35} \mathrm{~S}$ Label; ICN Biochemicals, Costa Mesa, CA) into the right eye as described previously (Brady, 1985). Injections were made with a 30 gauge needle connected to a Hamilton syringe by a length of PE20 tubing. Injection-sacrifice intervals (ISIs) were chosen to catch the peak of the slow component a (SCa) or slow component b ( $\mathrm{SCb}$ ) wave in the optic nerve and tract. ISIs used were $4-7 \mathrm{~d}$ for $\mathrm{SCb}$, and 18,21 , and $24 \mathrm{~d}$ for SCa. Two to five mice were analyzed at each time point. Mice were euthanized under anesthesia, then the optic nerve and tract were dissected.

The nerve and tract were cut into $1 \mathrm{~mm}$ long segments, and each segment was homogenized individually in $200 \mu \mathrm{l}$ BUST $(2 \%$ $\beta$-mercaptoethanol, $8 \mathrm{~m}$ urea, $1 \%$ SDS, $0.1 \mathrm{~m}$ Tris, and $0.02 \%$ phenol red). A $5 \mu \mathrm{l}$ aliquot of each homogenate was counted in a liquid scintillation counter, and equal aliquots of each segment were separated by SDS-PAGE on $4-16 \%$ (0-6 $\mathrm{M}$ urea) gradient gels. The gels were stained with Coomassie blue and destained, then processed for fluorography by dehydration in dimethylsulfoxide (DMSO; $2 \times 30 \mathrm{~min}$ ), impregnation with diphenyl oxazole (22\% in DMSO, $3 \mathrm{hr}$ ) and rehydration (Laskey and Mills, 1975). The gels were then dried and exposed to preflashed x-ray film (Eastman Kodak, Rochester, NY) for the appropriate time. The amount of radioactivity incorporated into specific proteins was quantitated by excising the appropriate bands from the gel using the fluorograph as a template. The bands were solubilized in $30 \%$ hydrogen peroxide for $2 \mathrm{~d}$ at $60^{\circ} \mathrm{C}$ and counted in a liquid scintillation counter. In some cases, the fluorograph was analyzed by laser densitometry (Molecular Dynamics, Sunnyvale, CA).

To permit comparison of transport for individual proteins down the optic nerve in different animals, the total radioactivity in segments was summed, and then the segment containing the $50 \%$ point of radioactivity was determined (Hoffman et al., 1983). The distance of the $50 \%$ point from cell bodies was then divided by the ISI to determine the rate of movement. Data for all SCa or SCb time points were averaged, and statistical significance for differences between rates was determined by a two-sample $t$ test using DataDesk software. Data are expressed as the mean \pm SEM.

Quantitative immunoblots. Nerve segments were homogenized in SUB buffer $(0.5 \%$ SDS, $8 \mathrm{~m}$ urea, and $2 \% \beta$-mercaptoethanol), then electrophoresed on 0.75 -mm-thick $6 \%$ polyacrylamide gels essentially as described previously (Cole et al., 1994). Each lane was loaded with $\sim 10 \mu \mathrm{g}$ of nerve protein. Levels of neurofilament subunits were analyzed by quantitative immunoblots.

After electrophoresis, proteins were transferred to nitrocellulose and probed with a monoclonal antibody specific for a highly phosphorylated neurofilament $\mathrm{H}(\mathrm{NFH})$ epitope, RM024, which has been previously characterized (Lee et al., 1986, 1987). To quantitate levels of different NF epitopes, immunoblots were washed five times for 3 min each in GB buffer (50 mu triethanolamine, 0.5\% Triton X-100, $0.1 \mathrm{~m} \mathrm{NaCl}, 2 \mathrm{~mm}$ K-EDTA, and $0.1 \%$ SDS, $\mathrm{pH} 7.5)$ and once in PTX buffer $(10 \mathrm{~mm}$ $\mathrm{NaPO}_{4}, \mathrm{pH} 7.5,0.2 \%$ Triton X-100, $0.15 \mathrm{~m} \mathrm{NaCl}$, and $1 \mathrm{~mm}$ EGTA). Blots were then incubated at room temperature in ${ }^{125}$ I-goat anti-mouse $\operatorname{IgG}\left(2 \times 10^{6} \mathrm{dpm} / \mathrm{ml}\right)$ in PTX buffer supplemented with $4 \%$ bovine serum albumin. After incubation, immunoblots were washed again five times for $3 \mathrm{~min}$ in GB buffer. Finally, blots were exposed to a PhosphorImager phosphor screen, the screens were digitized on a PhosphorImager, and radioactive bands were analyzed using the ImageQuant software (Molecular Dynamics, Sunnyvale, CA). The amount of immunoreactivity was evaluated by comparing shiverer, $\mathrm{MBP} / \mathrm{MBP}$ transgenic, and wild-type samples on the same blot.

Northern analyses. An NFH-specific probe was obtained using PCR with forward (GCTGAAGCCAAATCTCCAGCTAC) and reverse (AGGACTTTCACCTGCTCAGGG) primers directed against the C-terminal KSP repeat region of NFH. A $15 \mathrm{~kb}$ genomic fragment (a gift 
of Dr. Jean-Pierre Julien, McGill University, Montreal, Quebec, Canada) was used as a starting template with primers. A $612 \mathrm{bp} \mathrm{NFH} \mathrm{probe}$ was generated using 30 cycles with $45 \mathrm{sec}$ at $94^{\circ} \mathrm{C}, 1 \mathrm{~min}$ at $61^{\circ} \mathrm{C}$, and 1 min $30 \mathrm{sec}$ at $73^{\circ} \mathrm{C}$. A neurofilament $\mathrm{M}(\mathrm{NFM})$ probe was made by amplifying a 355 nucleotide product from a $0.66 \mathrm{~kb}$ NFM cDNA fragment originally cloned by Dr. Jean-Pierre Julien subcloned into a pUC8 vector. Forward and reverse primers were, respectively: CAGGATCTCCTTAACGTCAAGATGG and TTTCGGCTTCTGGTTCCTCCTC. The NFM probe was generated using 30 cycles with $45 \mathrm{sec}$ at $94^{\circ} \mathrm{C}, 1 \mathrm{~min}$ at $58^{\circ} \mathrm{C}$, and $1 \mathrm{~min} 30 \mathrm{sec}$ at $73^{\circ} \mathrm{C}$ with $3 \mathrm{~mm} \mathrm{MgCl}_{2}$. A 486 bp neurofilament L (NFL) probe was generated from a $1.2 \mathrm{~kb}$ NFL cDNA originally cloned by Dr. Nicolas Cowan inserted in puC8. Conditions used were similar to those used for the NFM probe, except that the reaction mix used $7 \mathrm{~mm} \mathrm{MgCl}_{2}$. TCAGTTTCACCAGCGTGGGTAG was the forward primer, and TGATGAGGTTGACCTGATTGGG was the reverse primer. A GAPDH oligomer with sequence CAGGGGGGCTAAGCAGTTGGTGGTGCAGGATGCATTGCTG was used to control for load. PCR products were labeled to a specific activity of $2-2.5 \times 10^{9} \mathrm{dpm} / \mu \mathrm{g}$ using $\alpha-\left[{ }^{32} \mathrm{P}\right] \mathrm{dCTP}(3000 \mathrm{Ci} / \mathrm{mmol}$; Amersham, Arlington Heights, IL) and a random nonamer kit (Readiprime; Amersham). Oligomers were labeled to a specific activity of $2.5-2.9 \times 10^{9} \mathrm{dpm} / \mu \mathrm{g}$ in a T4 kinase end labeling reaction.

Total RNA was isolated from mouse cortex using standard protocols for guanidinium extraction as described previously (Chomczynski and Sacchi, 1987). Five micrograms of total RNA from each animal were run on a $1 \%$ agarose-formaldehyde denaturing gel and transferred to a nylon membrane (Nytran; Schleicher \& Schuell, Keene, NH) in $20 \times$ SSC. RNA was UV-crosslinked to the membrane at $150 \mathrm{~mJ}$. Membranes were fixed in 5\% acetic acid, stained in methylene blue, and rinsed in DEPCtreated water to assess RNA transfer. To prevent probe cross reaction, blot lanes were cut into two sections: one for the neurofilament-specific probe and one for loading control. Each was prehybridized at $65^{\circ} \mathrm{C}$ for a minimum of $2 \mathrm{hr}$ in buffer containing $5 \times$ SSPE, $5 \times$ Denhardt's solution, $0.5 \% \mathrm{SDS}$, and $20 \mu \mathrm{g} / \mathrm{ml}$ sheared herring sperm DNA. Blots were incubated overnight at $65^{\circ} \mathrm{C}$ with $2 \times 10^{6} \mathrm{cpm} / \mathrm{ml}{ }^{32} \mathrm{P}$-labeled probes, washed to a final stringency of $2 \times \mathrm{SSC}, 0.2 \%$ SDS at room temperature, and exposed on a PhosphorImager (Molecular Dynamics) screen. Relative amounts of neurofilaments were calculated by determining the ratio of the intensity of the neurofilament and GAPDH signals after background subtraction.

Electron microscopy and morphometry of mouse optic nerve. Optic nerves were processed for electron microscopy essentially as described previously for sciatic nerves (de Waegh et al., 1992). Anesthetized mice were euthanized. Optic nerves were immediately removed, cut into 1-2 $\mathrm{mm}$ segments, and placed into freshly made fixative $(2 \%$ paraformalde-

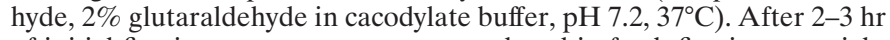
of initial fixation, nerve segments were placed in fresh fixative overnight at $4^{\circ} \mathrm{C}$. The nerves were post-fixed with $1 \%$ osmium tetroxide, dehydrated, and embedded in Epon. Thin sections were cut, counterstained with uranyl acetate and lead citrate, and viewed with a JEOL 1200SX electron microscope. Axons cut in cross-section were photographed at $50,000 \times$.

Neurofilament and microtubule densities were quantitatively evaluated in Shiverer, MBP/MBP transgenic, and wild-type mouse optic nerve axons as described previously (Price et al., 1988; de Waegh and Brady, 1991; de Waegh et al., 1992). Briefly, a transparency with evenly spaced hexagons was placed over electron micrographs printed at a final magnification of $140,000 \times$. At this magnification, each hexagon represents $0.035 \mu \mathrm{m}^{2}$ of axoplasm. All hexagons for which $>90 \%$ of their area was within axonal boundaries, membrane-bounded organelles occupied $<10 \%$ of the space, and the neurofilaments and microtubules cut in true cross-section were used. The number of neurofilaments or microtubules present in each of the suitable hexagons was counted. At least 60 axons (370 hexagons) were counted for each mouse type. The average number of neurofilaments or microtubules per hexagon was calculated by dividing the total number counted by the total number of hexagons. Additionally, the number of myelin wraps was noted for each axon counted. All values are expressed \pm SEM. Significant differences were determined by a two-sample $t$ test using Data Desk software.

\section{RESULTS}

Cytoskeletal proteins of the axon are moved with one of the slow axonal transport rate components: tubulin and neurofilament proteins move in $\mathrm{SCa}$, whereas some tubulin and actin move in
A.

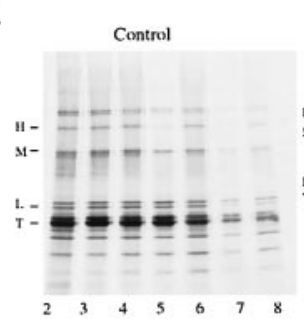

21 Days Transport
MBP/MBP

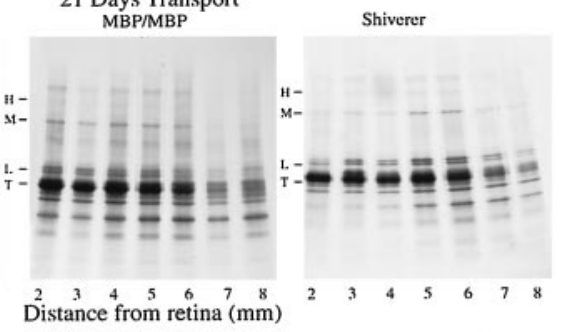

B.
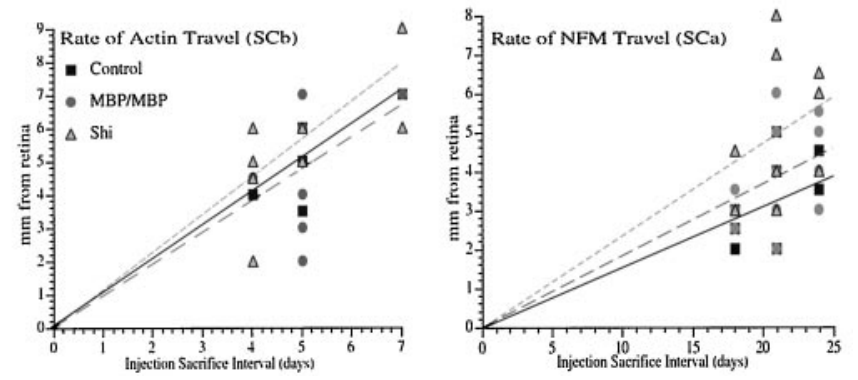

Figure 1. $\mathrm{SCa}$ and $\mathrm{SCb}$ rates are increased in shiverer relative to control and MBP/MBP shiverer transgenic rates. $A$, Slow axonal transport rates were examined by segmental analysis. $\left[{ }^{35} \mathrm{~S}\right]$ methionine was injected into the vitreous of the mouse eye, and $21 \mathrm{~d}$ after injection, optic nerve and tracts were harvested and cut into $1 \mathrm{~mm}$ segments. Radioactively labeled proteins in each segment were resolved on SDS-PAGE gels, processed for fluorography, and exposed to film. Fluorographs of control, MBP/MBP shiverer transgenic, and shiverer animals show the wave of radioactively labeled SCa proteins traveling down the optic nerve and tract. The positions for neurofilament subunits $(\mathrm{H}, \mathrm{M}$, and $\mathrm{L})$ and tubulin doublet (T) are distributed as a wave in all three animals $21 \mathrm{~d}$ after injection. Note that the peaks for NFH and NFM are in axon segments 3-4 mm for control and MBP/MBP nerves, but are in segments 5-6 mm for shiverer. Similarly, the peak of tubulin is $4 \mathrm{~mm}$ in control and MBP/MBP shiverer transgenic animals but $5.5 \mathrm{~mm}$ in shiverer animals. Note that NFH is barely detectable in shiverer and MBP/MBP animals when compared to control, but NFL levels are comparable. $B$, Distance from retina for labeled peaks of actin at 4, 5, and 7 (actin) and for NFM at 18, 21, and $24 \mathrm{~d}$ after labeling. Data are plotted for shiverer (triangles), MBP/MBP transgenics (circles), and wild-type control (filled squares), where each symbol is data from a different animal, and two to five animals were used for each time point. A best fit line passing through zero is shown for shiverer (short dashed line, triangle), MBP/MBP transgenic (long dashed line, circle), and wild-type control (solid line, filled square). The slope of this line represents the rate of slow transport.

SCb (Brady, 1993). Measurement of slow axonal transport in demyelinated PNS fibers of Trembler mice found a transport rate for cytoskeletal proteins significantly slower than wild-type controls. To determine whether CNS myelin affected transport of cytoskeletal proteins similarly, transport rates were analyzed in optic nerves and tracts of shiverer, MBP/MBP transgenic, and wild-type mice as described previously (Brady, 1985). Briefly, 0.5 $\mathrm{mCi}\left[{ }^{35} \mathrm{~S}\right] \mathrm{methionine}$ was injected into the vitreous of the eye to pulse label proteins synthesized in retinal ganglion cells. At various intervals after labeling, the optic nerve and tract were dissected and cut into $1 \mathrm{~mm}$ segments for gel electrophoresis. Radioactive polypeptides in each nerve segment were visualized by fluorography (Fig. $1 A$ ) and fluorographs used to estimate rates of transport for cytoskeletal proteins: measuring neurofilament and microtubule protein distribution for $\mathrm{SCa}$ and measuring actin distribution for $\mathrm{SCb}$.

Although rates for neurofilament transport in SCa were slower in Trembler sciatic nerve, labeled neurofilament subunits had moved further along shiverer nerves than along control nerves at the same time point (Fig. $1 A$ ), indicating a faster rate of trans- 
Table 1. Slow axonal transport rates for neurofilament and microfilament subunits in shiverer, MBP/MBP shiverer transgenic, and wild-type mouse optic nerve (rates in millimeters per day)

\begin{tabular}{llll} 
& Shiverer & MBP/MBP & Wild-type \\
\hline SCa: Neurofilament protein (NFM) & $0.20 \pm 0.02^{a} n=5$ & $0.17 \pm 0.03 n=8$ & $0.17 \pm 0.03 n=6$ \\
SCb: Actin & $0.95 \pm 0.07^{b} n=4$ & $0.83 \pm 0.07 n=6$ & $0.86 \pm 0.13 n=7$ \\
SCb: Spectrin & $0.96 \pm 0.08^{c} n=4$ & $0.74 \pm 0.11 n=6$ & $0.82 \pm 0.12 n=7$
\end{tabular}

The average distance travelled by $50 \%$ of the label associated with marker proteins for $\mathrm{SCa}$ and $\mathrm{SCb}$ was determined by cutting specific molecular weight bands out of the fluorographs (Fig. 1A) and counting the amount of radioactivity incorporated into each protein. Rates of travel were calculated by dividing the distance by the time between radiolabel injection and the sacrifice of the animal $(4,5$, and $7 \mathrm{~d}$ for SCb proteins and 18, 21, or $24 \mathrm{~d}$ for SCa proteins). Data is expressed as the mean \pm SEM.

${ }^{a}$ Shiverer NFM rate significantly different from MBP/MBP rate at $p=0.03$ and from wild-type at $p=0.05$.

${ }^{b}$ Shiverer actin rate significantly different from MBP/MBP rate at $p=0.05$.

${ }^{c}$ Shiverer spectrin rate significantly different from MBP/MBP rate at $p=0.008$ and from wild-type at $p=0.03$.
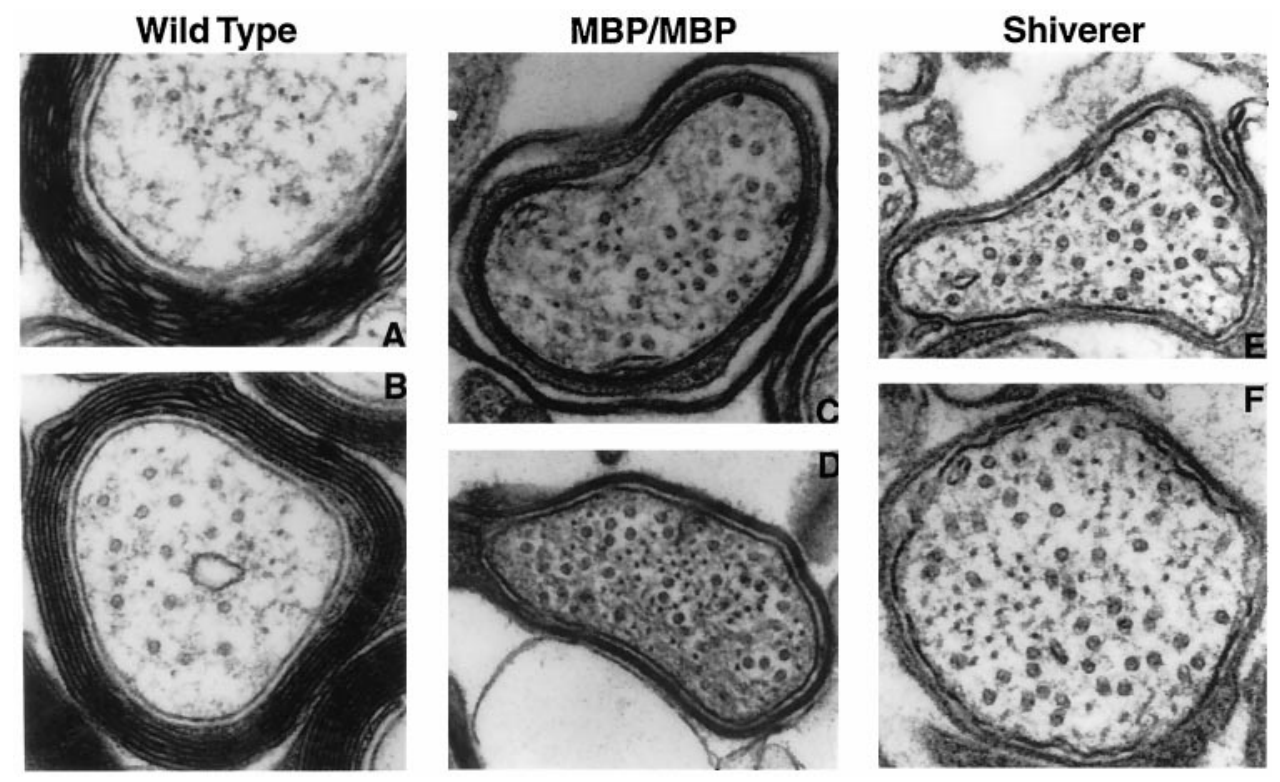

Figure 2. Axonal neurofilament and microtubule organization and numbers are altered in MBP/MBP shiverer transgenic and shiverer optic axons relative to control. Typical axonal cytoskeletons are shown in electron micrographs of optic nerve axonal cross sections from wild-type $(A, B)$, MBP/MBP transgenic $(C, D)$, and shiverer $(E, F)$ mice. The number and density of microtubules (arrow) are significantly increased in MBP/MBP transgenic and shiverer axons relative to wild-type control axons. Neurofilament organization (arrowhead) appears altered to produce increased density, although these changes are less dramatic than those seen with microtubules. Neurofilament numbers may be depressed in the shiverer and MBP/MBP transgenic axons. Compare the completely myelinated axons in control to the partially myelinated axons of MBP/MBP shiverer transgenic animals and unmyelinated axons of shiverer. Although the density of extracellular material appears similar in micrographs from each category of mouse, the electron density of axoplasm appears greatest in MBP/MBP transgenics and is also increased in shiverer axons. Scale bar, $0.19 \mu \mathrm{m}$.

port. Similar changes were seen for distribution of tubulin in SCa (Fig. $1 A$ ) and for actin and various other SCb proteins (including spectrin and clathrin; data not shown). In contrast to the shiverer, distributions of labeled cytoskeletal proteins in MBP/MBP transgenic nerves were the same as wild-type for all proteins examined (Fig. 1A), indicating that the formation of compact myelin was sufficient to alter slow axonal transport rates even when myelin thickness was only $25 \%$ of normal.

Rates of transport for actin and NFM may be estimated by plotting the distance of their labeled peaks at 4, 5, and 7 (actin) or 18, 21, and $24 \mathrm{~d}$ (NFM) after labeling (Fig. 1B), where the slope of the line corresponds to the rate. For both actin and NFM, the slope was greatest for the shiverer nerves, whereas wild-type and MBP/MBP slopes were almost the same. Alternatively, rates of transport may be calculated by measuring how far $50 \%$ of the labeled protein had moved at each time point (Table 1). By this measure, NFM moved at $0.20 \pm 0.02 \mathrm{~mm} / \mathrm{d}$ in shiverer, which was significantly different ( $p \leq 0.05$ using a two-sample $t$ test) from the rate of $0.17 \pm 0.03 \mathrm{~mm} / \mathrm{d}$ seen in both wild-type and $\mathrm{MBP} /$
MBP. Similarly, actin and spectrin moved at $\sim 0.95 \mathrm{~mm} / \mathrm{d}$ in shiverer nerves, but only $0.75-0.85 \mathrm{~mm} / \mathrm{d}$ in wild-type and $\mathrm{MBP} /$ MBP nerves (Table 1). The fact that even reduced levels of compact myelin were sufficient to restore axonal transport to near wild-type is consistent with observations on suppression of tremor and extension of life span in the transgenic (Readhead et al., 1987).

A different impression emerged from electron microscopic analysis of nerves on these three types of mouse. Figure 2 shows axonal cross sections from the optic nerve of wild-type $(A, B)$, $\mathrm{MBP} / \mathrm{MBP}$ transgenic $(C, D)$, and shiverer $(E, F)$ mice. The absence of compact myelin in shiverer is apparent, although oligodendrocyte processes can be seen to wrap each axon. By comparison, $\mathrm{MBP} / \mathrm{MBP}$ nerves typically have only a few lamellae of compact myelin, much reduced relative that seen in control nerves. However, even qualitative examination of cytoskeletal elements in the axons indicate that shiverer and MBP/MBP fibers resemble each other far more than either resembles wild-type fibers. Microtubules are much more abundant than in wild-type 
A.

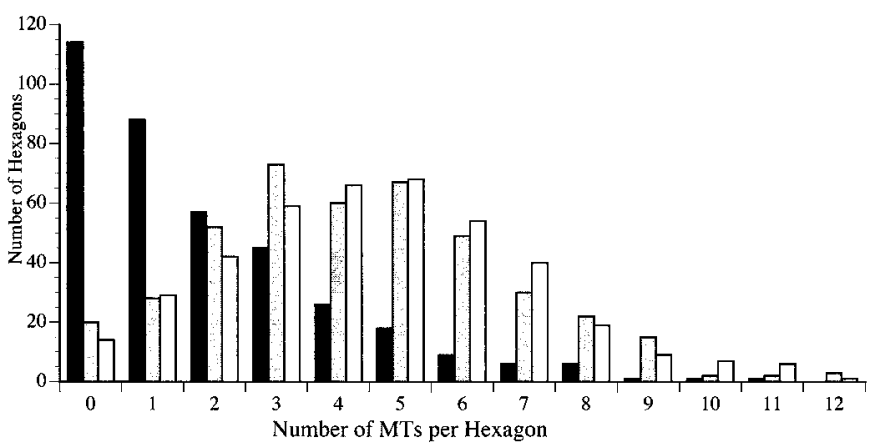

B.

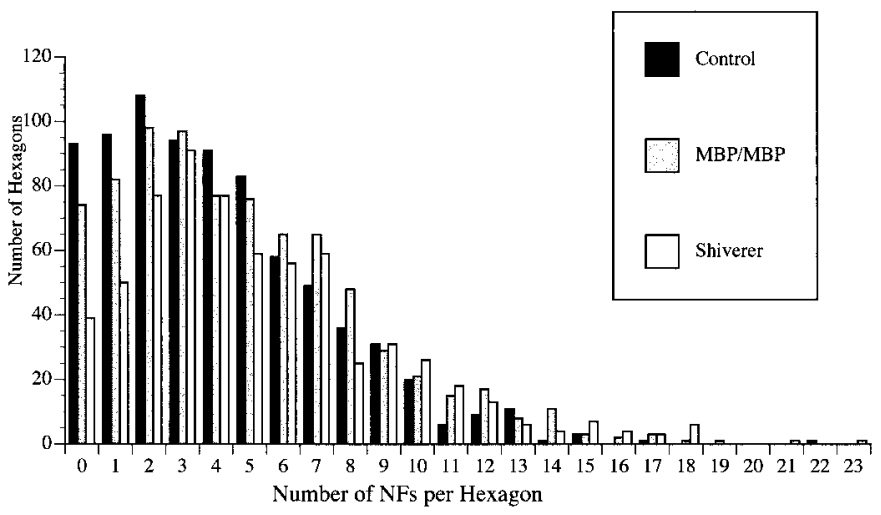

Figure 3. Morphometric analyses show changes for both microtubule and neurofilament density in shiverer and $\mathrm{MBP} / \mathrm{MBP}$ shiverer transgenic axons. As a measure of cytoskeletal organization, the density of microtubules and neurofilaments was examined as described previously (de Waegh et al., 1992). The number of cytoskeletal elements in random hexagons was evaluated. Both microtubules and neurofilament densities are shifted to higher values in shiverer axons. $A$, Microtubule distributions were similar in shiverer and $\mathrm{MBP} / \mathrm{MBP}$ transgenic nerves. The mean number of microtubules per hexagon was increased in both MBP/MBP transgenic $(4.38 \pm 0.05 ; \pm \mathrm{SEM})$ and shiverer $(4.53 \pm 0.05$; \pm SEM $)$ axons. These differences were significant at $p \leq 0.0001$ (two-sample $t$ test) when compared to the wild-type control value of $1.9 \pm 0.07$ ( \pm SEM) MT per hexagon. $B$, Unlike microtubules, the neurofilament distribution in $\mathrm{MBP} / \mathrm{MBP}$ transgenic nerves was intermediate between shiverer and wild-type control nerves. The mean number of neurofilaments per hexagon was also significantly greater in shiverer $(4.39 \pm 0.06 ; \pm$ SEM neurofilaments per hexagon) and MBP/MBP shiverer transgenic (4.75 \pm $0.05 ; \pm$ SEM neurofilaments per hexagon; in a paired $t$ test relative to wild-type control) than in control $(4.11 \pm 0.05$ neurofilaments per hexagon). Differences relative to wild-type control axons are significant at $p \leq$ 0.0001 (shiverer) and $p=0.002(\mathrm{MBP} / \mathrm{MBP}$ transgenic) in a paired $t$ test. Morphometric analyses were conducted by overlaying a hexagonal grid over electron micrographs of the optic axonal cross sections printed at a final magnification of $140,000 \times$. Each hexagon represented an area of $0.035 \mu \mathrm{m}^{2}$. The number of microtubules and neurofilaments per hexagon was scored, binned, and plotted. The number of microtubules per hexagon ranged between 0 and 12 , whereas the number of neurofilaments per hexagon ranged from 0 to 23 .

and appear closer to each other, whereas the axoplasm of both shiverer and MBP/MBP fibers has an increased electron density.

Differences in axonal microtubules and neurofilaments were even more striking in quantitative morphometric analyses. The similarities between shiverer and $\mathrm{MBP} / \mathrm{MBP}$ mice are readily seen in the density distribution of microtubules in optic axons of shiverer, MBP/MBP, and wild-type mice (Fig. $3 A$ ). The mean number of microtubules per unit hexagon in shiverer was 4.4 and in $\mathrm{MBP} / \mathrm{MBP}$ was 4.5 . Each of these was significantly different from the mean of 1.9 microtubules per hexagon for wild-type axons with a $p \leq 0.0001$ using a two-sample $t$ test. These values indicate that axons in shiverer and $\mathrm{MBP} / \mathrm{MBP}$ nerves averaged 20-21 microtubules per axon, whereas wild-type axons averaged only 10-11 microtubules per axon.

Differences in neurofilament density could also be seen (Fig. $3 B$ ), but in this case $\mathrm{MBP} / \mathrm{MBP}$ neurofilament densities were intermediate between those of shiverer and wild-type. The mean number of neurofilaments per unit hexagon in shiverer ( \pm SEM) was $4.85 \pm 0.06$ and in $\mathrm{MBP} / \mathrm{MBP}$ was $4.63 \pm 0.05$, as opposed to a mean of $4.11 \pm 0.05$ neurofilaments per hexagon in wild-type axons. The mean of shiverer neurofilaments per hexagon was significantly different from both wild-type and transgenic with a $p \leq 0.0001$ in a paired $t$ test, whereas the difference between wild-type and $\mathrm{MBP} / \mathrm{MBP}$ was significant at $p \leq 0.002$. As previously seen in the PNS with Trembler, neurofilament density increases in the absence of compact myelin. In contrast to the large increase in numbers of microtubules per axon, numbers of neurofilaments per axon were slightly depressed in shiverer axons with an average of 34-35 neurofilaments per axon in shiverer, 39-40 neurofilaments per axon in MBP/MBP, and 43-44 neurofilaments per axon in wild-type axons.

The axonal transport experiments (Fig. $1 A$ ) not only showed an increased rate of transport for neurofilaments in shiverer, but also suggested that neurofilament subunit composition was altered. When the amount of radiolabel associated with each subunit was expressed as a fraction of total radiolabeled SCa proteins in optic nerve (Fig. $4 A$ ), the relative amount of $\mathrm{NFH}$ was reduced in shiverer and transgenics. The mean level of NFH was essentially the same in shiverer and $\mathrm{MBP} / \mathrm{MBP}$ transgenics. However, the difference between transgenics and wild-type was significant at $p=0.037$ using a two-sample $t$ test, whereas the difference between shiverer and wild-type was significant only at $p=0.051$ because of the greater scatter in data from shiverer. In contrast, relative amounts of NFM were reduced in shiverer nerves relative to both wild-type and MBP/MBP transgenics (differences were significant at $p=0.035$ and $p \leq 0.0001$, respectively in a two-sample $t$ test). NFM protein levels in MBP/MBP nerves were actually elevated over wild-type levels (difference significant at $p=0.04$ in a two-sample $t$ test). Although higher molecular weight subunits were decreased in shiverer, NFL levels were slightly but significantly elevated in shiverer nerves over both wild-type $(p=0.026)$ and $\mathrm{MBP} / \mathrm{MBP}(p \leq 0.013$, both using a two-sample $t$ test). Based on a similar analysis, amounts of tubulin protein present in shiverer and $\mathrm{MBP} / \mathrm{MBP}$ nerves were also significantly increased over wild-type (L. L. Kirkpatrick, A. S. Witt, C. Readhead, and S. T. Brady, in preparation).

These values may be used to calculate the relative contribution of each subunit to total neurofilament mass in the three mouse strains (Fig. 4B). NFH represented only $8 \%$ of the mass for shiverer and MBP/MBP neurofilaments, but comprised $12 \%$ of wild-type neurofilaments. Increased NFM levels in MBP/MBP nerves mean that NFM constituted a greater fraction of the neurofilaments in transgenic nerves $(33 \%)$ than of those in either shiverer $(20 \%)$ or wild-type $(27 \%)$. Similarly, shiverer neurofilaments included a greater proportion of NFL (73\%), whereas the contribution of NFL to MBP/MBP and wild-type was comparable (59 and $61 \%$, respectively).

Differences in cytoskeletal protein levels seen in shiverer and $\mathrm{MBP} / \mathrm{MBP}$ nerves could have been caused by changes in either cytoskeletal gene expression or protein degradation. When levels of NFH and NFM mRNA were analyzed by Northern blot 
A.
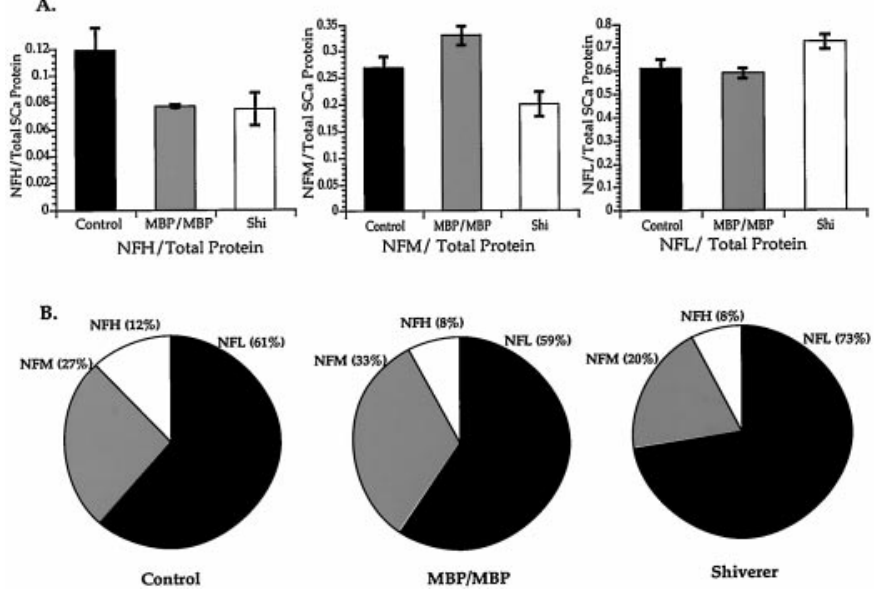

Figure 4. Neurofilament protein levels and neurofilament composition are changed in MBP/MBP shiverer transgenic and shiverer animals relative to control. The amount of NFH, NFM, and NFL protein in nerves expressed as a fraction of the total protein moving with SCa was determined by densitometry of fluorographs from axonal transport studies in wild-type control, $\mathrm{MBP} / \mathrm{MBP}$ transgenic, and shiverer mice. $A, \mathrm{NFH}$ protein levels are decreased relative to wild-type control in both MBP/ MBP transgenic and shiverer ( $n=17 ; n=24$; and $n=17$, respectively). The differences in NFH for shiverer was different from wild-type at $p=$ 0.051 , whereas MBP/MBP transgenics were different at $p=0.037$. Shiverer and transgenics had a similar mean value for $\mathrm{NFH}$, but the shiverer data had greater scatter. NFM levels were decreased in shiverer mice relative to both wild-type $(p=0.035)$ and transgenics $(p \leq 0.0001)$, but NFM in MBP/MBP transgenic animals was increased over wild-type $(p=0.04)$. NFL levels were not distinguishable between wild-type control and $\mathrm{MBP} / \mathrm{MBP}$ transgenics, but were increased slightly in shiverer relative to both wild-type control $(p=0.026)$ and MBP/MBP transgenics (difference significant at $p \leq 0.0001$ ). All comparisons were made using a two-sample $t$ test. $B$, Changes in the relative contributions of NFH, NFM, and NFL proteins to neurofilament mass illustrate changes in composition. A larger proportion of shiverer neurofilament consists of NFL subunits, whereas in control animals the contribution of NFH to the neurofilament mass is greater than either $\mathrm{MBP} / \mathrm{MBP}$ transgenic or shiverer neurofilaments. Similarly, in MBP/MBP shiverer transgenic the contribution of NFH to neurofilament mass is comparable to that in shiverer, but the NFM content is greater than in either control or shiverer animals.

analyses of total RNA fractions from shiverer, MBP/MBP, and wild-type CNS tissue (Fig. 5), striking differences were seen. A probe specific for $\mathrm{NFH}$ recognized a $4.0 \mathrm{~kb}$ message, and the same blots were analyzed with a GAPDH probe to allow normalization for RNA load (Fig. 5A). When expressed as a ratio to wild-type levels, shiverer NFH mRNA levels were significantly reduced ( $p=0.029$ using a paired $t$ test) (Fig. $5 B$ ). The mean level of NFH message in MBP/MBP tissue was also reduced (Fig. $5 B)$, but the observed differences were not statistically significant at the $p \leq 0.05$ level $(n=5)$. These results indicate that either transcription or stability of NFH mRNA is sensitive to the level of myelination.

Although NFM protein levels were depressed in shiverer and slightly elevated in $\mathrm{MBP} / \mathrm{MBP}$, parallel analyses of the $3.5 \mathrm{~kb}$ NFM message showed a different pattern for NFM mRNA expression quite different from that seen for NFH (Fig. 5C). After normalizing for RNA load by comparison with GAPDH, levels of NFM message in the CNS (Fig. 5D) were essentially the same as wild-type for both MBP/MBP (1.09 \pm 0.05$)$ and shiverer $(1.15 \pm$ $0.07)$. The slight increases were not statistically significant at $p \leq$ 0.05 using a paired $t$ test $(n=11)$. These results suggest that
A.

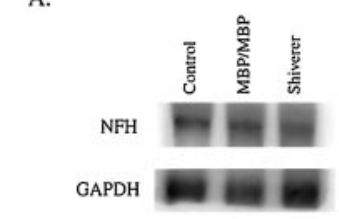

C.

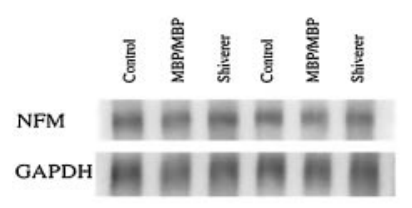

B.

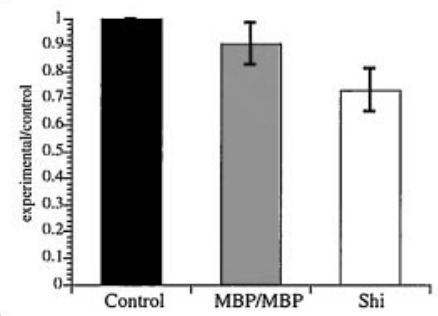

D.

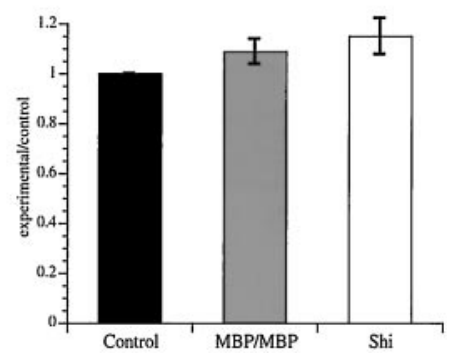

Figure 5. Expression levels of NFH are significantly reduced in shiverer as opposed to wild-type control. The reduced levels of NFH polypeptide in shiverer and MBP/MBP transgenic is reflected in reduced levels of NFH mRNA. In contrast, NFM mRNA is not significantly different from wild-type control in either shiverer or $\mathrm{MBP} / \mathrm{MBP}$ transgenic animals. $A$, Northern blot of NFH and the GAPDH loading control. The expression of the $4.0 \mathrm{~kb} \mathrm{NFH}$ transcript appeared to be reduced in shiverer when compared to control or MBP/MBP transgenic animals. The NFH mRNA levels in MBP/MBP transgenic appeared to be slightly reduced. Each lane contains $5 \mu \mathrm{g}$ of total RNA isolated from the cortices of age-matched animals. $B$, Quantitation of the NFH expression levels $(n=5)$. After normalizing with GAPDH, a ratio of NFH expression was calculated, and the expression level of shiverer and MBP/MBP shiverer transgenic was normalized to control expression levels. The levels of NFH expression were significantly reduced in shiverer relative to control $(p=0.029$ in a paired $t$ test). Although levels of NFH expression in MBP/MBP shiverer transgenic animals were consistently reduced as opposed to wild-type control and consistently higher than shiverer NFH expression levels, the differences were not significant at $p \geq 0.05$. $C$, Northern blot of NFM and GAPDH loading control. No consistent differences in mRNA expression levels were apparent. $D$, Quantitation of relative NFM levels in the three animals $(n=11)$. NFM levels were not significantly different in the three animal types.

either translation of NFM mRNA or the stability of NFM protein is sensitive to the level of myelination.

Because phosphorylation of neurofilaments in Trembler peripheral nerves is significantly reduced in demyelinated regions, we used antibodies sensitive to phosphorylation state of $\mathrm{NFH}$ in quantitative immunoblots. After compensating for differences in NFH protein levels by normalizing signals to wild-type levels, the level of relative phosphorylation for $\mathrm{NFH}$ could be examined in the corpus callosum and sciatic nerve of $\mathrm{MBP} / \mathrm{MBP}$ and shiverer mice based on immunoreactivity with the RMO24 monoclonal antibody, which recognizes only highly phosphorylated NFH (Lee et al., 1986). NFH phosphorylation was reduced in CNS axons of the corpus callosum, but was unaffected in PNS axons of the sciatic nerve (Fig. 6). The differences from wild-type control values in CNS tissue were significant using a paired $t$ test for both shiverer $(p=0.016)$ and MBP/MBP transgenics $(p=0.0014)$. These results indicate that deficient myelination locally reduces neurofilament phosphorylation in both CNS (shiverer and MBP/ MBP) and PNS (Trembler; de Waegh et al., 1992) fibers. Notably, the suboptimal CNS myelination seen in MBP/MBP transgenics was not sufficient to restore neurofilament phosphorylation to 


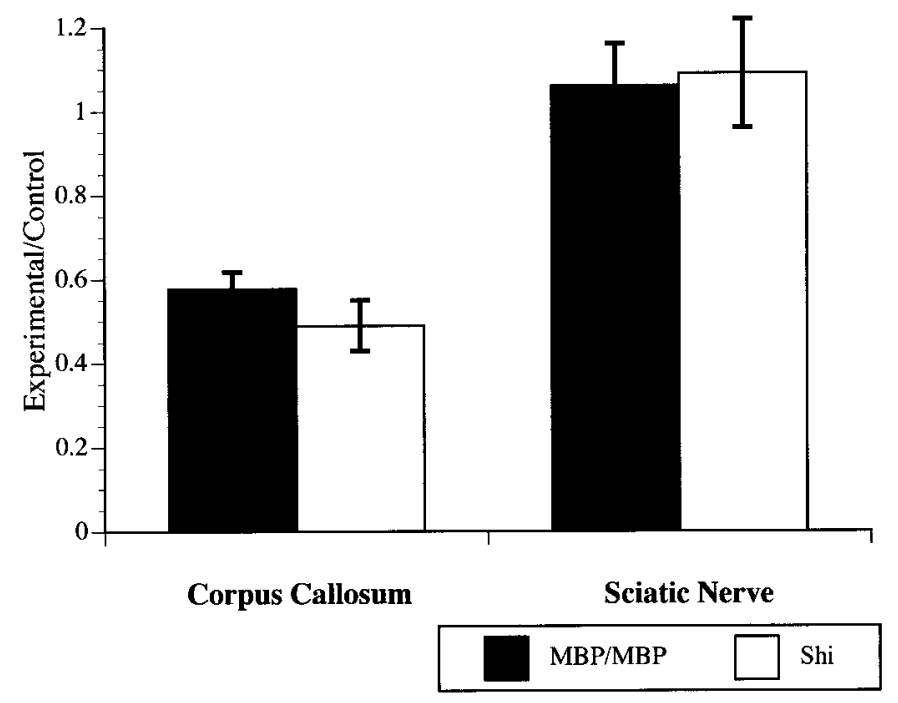

Figure 6. Quantitative immunoblot analysis of highly phosphorylated NFH antibody immunoreactivity in corpus callosum and sciatic nerve homogenates from MBP/MBP shiverer transgenic and shiverer relative to wild-type control. The relative phosphorylation of $\mathrm{NFH}$ was significantly reduced in CNS, but not in PNS axons. Whereas NFH levels were reduced in the CNS of $\mathrm{MBP} / \mathrm{MBP}$ transgenic and shiverer mice, the phosphorylation of the NFH present was roughly half that of wild-type controls. The differences from wild-type control values were significant at $p=016$ for shiverer and at $p=0.0014$ for MBP/MBP transgenics. Phosphorylation of NFH was not significantly different between MBP/ MBP transgenic and shiverer nerves. Approximately $10 \mu \mathrm{g}$ of corpus callosum or sciatic nerve homogenates was run on SDS-PAGE gels and transferred to nitrocellulose blots, then blotted with the RMO24 antibody, which is specific to highly phosphorylated NFH. This was followed by a radioactively labeled secondary antibody before being exposed to a PhosphorImager screen. The relative intensity of highly phosphorylated NFH immunoreactivity on the ensuing scans was determined. Highly phosphorylated NFH signals were normalized to NFL-immunoreactive signals that had been corrected for varying levels among the three animal types using the data in Figure 4. Each was plotted as the ratio of NFHimmunoreactive signal from $\mathrm{MBP} / \mathrm{MBP}$ or shiverer to control. All values were corrected for the varying amounts of NFH protein levels among the three animal types using the data in Figure 4 before calculation of phosphorylation ratios. For corpus callosum samples, $n=32$ for shiverer animals, $n=21$ for MBP/MBP animals, and $n=17$ for control animals. For sciatic nerve samples, $n=32$ for shiverer, $n=20$ for MBP/MBP, and $n=18$ for control animals.

normal levels. In the Trembler mouse, graft studies demonstrated that differences in phosphorylation of neurofilaments was caused by differences in local activity (de Waegh and Brady, 1991). Although a similar mechanism may well be operational in shiverer axons, the observed effects of myelination on neuronal gene expression raise the possibility that altered neurofilament phosphorylation shiverer axons could be caused by changes in the expression of kinases or phosphatases. Because similar graft studies are not currently feasible in the CNS, resolution of this issue will require alternative approaches.

In summary, a wide range of axonal and neuronal parameters were altered in the CNS of myelin-deficient shiverer mice, including rates of axonal transport, organization, and composition of the axonal cytoskeleton, posttranslational modification of cytoskeletal proteins, and cytoskeletal gene expression in the neuronal cell body. The reduced level of myelination found in the $\mathrm{MBP} / \mathrm{MBP}$ transgenic mouse was sufficient to restore some parameters to wild-type levels (slow axonal transport rates and NFM protein levels), but not sufficient to restore others (such as microtubule numbers and NFH protein levels). Despite these alterations in the composition and architecture of CNS axons in the $\mathrm{MBP} / \mathrm{MBP}$ transgenic mouse, the reduced level of myelination in transgenics was sufficient to restore normal life span and minimize tremors.

\section{DISCUSSION}

The effects of demyelination on the PNS axonal cytoskeleton in Trembler mutant mice (de Waegh and Brady, 1990; de Waegh, 1990; de Waegh and Brady, 1991) led to examination of similar parameters in optic axons of CNS myelin-deficient shiverer mutant mice. Shiverer mice lack myelin basic protein, an essential structural component of CNS myelin (Campagnoni and Macklin, 1988) and do not form CNS compact myelin. Many of the same parameters were altered in both shiverer and Trembler axons without myelin, but these changes were not always in the same direction, and additional characteristics were affected in shiverer myelin-deficient neurons. Because transgenic mice homozygous for an MBP transgene in a shiverer background have myelin sheaths significantly thinner than wild-type, the requirement for a myelin sheath of normal thickness was assessed in parallel studies. Surprisingly, some neuronal parameters were restored to wildtype values by a thin myelin sheath, whereas others were more like shiverer or intermediate between the two. Characteristics of neurons in both shiverer and $\mathrm{MBP} / \mathrm{MBP}$ transgenic mice are reminiscent of immature or unmyelinated axons, suggesting that myelinating glia play a role in differentiation of neurons with large axons.

Shiverer is a CNS myelin deficiency mouse mutant (Chernoff, 1981) resulting from a recombination within the MBP gene (Roach et al., 1985; Molineaux et al., 1986) that eliminates MBP expression (Roach et al., 1983; Kimura et al., 1985). Although MBP is normally present in PNS myelin, PNS myelination is near normal in MBP null mice (Rosenbluth, 1980), because PNSspecific proteins with overlapping function exist. However, differences do exist in shiverer PNS myelin fine structure, including mild hypomyelination and a significant increase in SchmidtLantermann cleft number (Gould et al., 1995). In contrast, MBP null mice have no compact myelin in their CNS (Shine et al., 1992). Absence of CNS myelination in shiverer leads to severe intention tremor and early death, typically within $100 \mathrm{~d}$ (Readhead and Hood, 1990). Although shiverer is the best characterized animal model with deficits in MBP expression, less severe alleles like $s h i^{\mathrm{mld}} / s h i^{\mathrm{mld}}$ (myelin deficient) mouse exist (Readhead and Hood, 1990), and transgenic mice have been generated that express varying levels of MBP (Popko et al., 1987; Readhead et al., 1987; Kimura et al., 1989). Availability of mouse models with different levels of MBP expression permits detailed analyses of myelination effects on CNS function (Popko et al., 1987; Shine et al., 1992).

Introduction of MBP transgenes into shiverer was the first genetic "cure" of a neurological mutant (Readhead et al., 1987). Shiverer mice homozygous for an MBP transgene have MBP mRNA and protein levels $\sim 25 \%$ of normal (Popko et al., 1987; Readhead et al., 1987). MBP/MBP transgenics produce compact myelin with morphologically normal major dense lines, but substantially reduced myelin sheath thickness. Optic axons typically have only two to four lamellae as opposed to 8-11 or more lamellae in wild-type. Even this modest investiture of compact myelin was sufficient to restore life spans of MBP/MBP mice to wild-type values and largely suppress intention tremor (Readhead et al., 1987). This showed that essential aspects of neuronal 
Table 2. Summary of changes in neuronal parameters for shiverer, transgenic shiverer, and wild-type mice

\begin{tabular}{llll} 
& Shiverer & MBP/MBP & Wild-type \\
\hline Myelin basic protein & 0 & 0.25 & 1.0 \\
Compact myelin lamellae & 0 & $2-4$ & $>10$ \\
Slow axonal transport & Increased & Normal & Normal \\
Microtubule number & $2 \times$ increase & $2 \times$ increase & Normal \\
Microtubule density & $2 \times$ increase & $2 \times$ increase & Normal \\
Neurofilament density & $1.2 \times$ & $1.1 \times$ & 1.0 \\
NFH expression & Decreased & Decreased & Normal \\
NFM expression & Decreased & Slight elevation & Normal \\
Neurofilament & & & \\
\multicolumn{1}{c}{ phosphorylation } & Decreased & Decreased & Normal \\
\hline
\end{tabular}

function can be reestablished by minimal myelination and was consistent with observations that even a thin myelin sheath allows saltatory conduction of action potentials (Shrager and Rubinstein, 1990). Initial observations on slow axonal transport rates reinforced this conclusion, because rates of transport in $\mathrm{MBP} /$ MBP optic nerves were indistinguishable from wild-type (Fig. 1).

Although normal axonal transport rates, minimal tremor, and normal life span of MBP/MBP mice all implied that any amount of compact myelin would restore axonal functionality, electron micrographs of optic nerves from shiverer, $\mathrm{MBP} / \mathrm{MBP}$, and wildtype mice (Fig. 2) led to a very different conclusion about axonal morphology. Differences between wild-type and MBP/MBP axons in ultrastructure, cytoskeletal organization, and cytoskeletal composition are as apparent as similarities between shiverer and $\mathrm{MBP} / \mathrm{MBP}$ axons. Differences in organization were confirmed by morphometric studies and prompted quantitative analysis of cytoskeletal composition. Neurofilament protein and mRNA levels were altered in shiverer and $\mathrm{MBP} / \mathrm{MBP}$ transgenic mouse CNS tissue. In contrast to Trembler PNS axons where levels of axonal neurofilament protein did not differ from controls (de Waegh et al., 1992), interactions between oligodendrocytes and axons during compact myelin formation significantly altered axon cytoskeletal composition as well as organization.

The shiverer axonal cytoskeleton is similar in many respects to the cytoskeleton of wild-type axons before myelination. NFH appears later in development than NFM and NFL (Shaw and Weber, 1982; Willard and Simon, 1983; Pachter and Liem, 1984), and rates for $\mathrm{SCa}$ and $\mathrm{SCb}$ are faster in immature fibers gradually slowing with maturation and aging (Hoffman et al., 1985). A significant upregulation of NFH mRNA (Hoffman et al., 1988) occurs postnatally, and immature neurofilaments have lower content of the NFH subunit than neurofilaments from adult nerves (Shaw and Weber, 1982; Pachter and Liem, 1984; Carden et al., 1987). Upregulation of NFH protein and slowing of slow axonal transport occur at $\mathrm{P}_{10}-\mathrm{P}_{20}$ in rodent optic nerve (Willard and Simon, 1983; Pachter and Liem, 1984; Carden et al., 1987), concurrent with myelination of these axons. The failure of shiverer to produce a mature CNS axonal cytoskeleton in combination with temporal correlation of maturation in wild-type development strongly suggests that formation of compact myelin is necessary for normal differentiation of neurons with large axons. This conclusion is strengthened by the intermediate phenotype seen with MBP/MBP axons (slower transport and higher NFM expression, whereas NFH expression continues to be altered; see Table 2 for summary of changes).
Altered cytoskeletal gene expression in shiverer and $\mathrm{MBP} /$ MBP indicated that signaling pathway or pathways exist by which myelinating glia influence CNS neuronal differentiation. Although some components of these pathways modify local properties of CNS axons like neurofilament phosphorylation, others affect events in the neuronal cell body. Changes in the neuronal perikaryon include altered levels of $\mathrm{NFH}$ mRNA presumably through effects on transcriptional regulation and changes in net translation of NFM mRNA. A previous report (Sanchez et al., 1996) suggested that oligodendrocyte influence on axonal caliber required contact, but not formation of compact myelin. However, this study focused on retinal ganglion cell axon segments as they emerge from the lamina cribosa. This is a transitional myelination region and is not representative of mature myelinated fibers. Regardless, data presented here demonstrate that simple contact between oligodendrocyte and axon is not sufficient.

Signaling pathways by which oligodendrocytes influence neurons remain to be determined. However, some characteristics of these pathways can be defined (Fig. 7). A locally acting component must affect specifically axonal kinase/phosphatase activities to produce observed local changes in neurofilament phosphorylation. A retrograde signaling component must also exist that is transported back to neuronal perikarya to influence neuronal gene expression at the level of translation and/or transcription. This second component may be generated either directly or indirectly (by modification of axonal components for return). Finally, activation of signaling pathways for communication between myelinating glia and axons must require intimate contacts associated with formation of compact myelin. This last element suggests a plausible model might be based on various receptorlinked kinases that affect gene expression in non-neuronal cells through phosphorylation cascades modifying transcription factors and other cellular targets.

While the transgenic shiverer mouse was termed a genetic rescue based on increased life span and suppression of tremor (Readhead et al., 1987), detailed analyses of axonal composition and morphology reveal a more complex situation (Table 2). Some features of transgenic axons like slow axonal transport and NFM expression are comparable to wild-type, but other parameters like expression of tubulin and NFH subunits remain more like shiverer (Figs. 1, 4, 5). Other parameters like neurofilament density are intermediate between shiverer and wild-type. This suggests that multiple pathways exist by which myelinating glia influence neuron and axons. Some characteristics are restored by formation of a thin myelin sheath such as that found in transgenic shiverers, but others are not activated until a thicker myelin sheath such as that found in wild-type has formed. While the genetic lesion is well characterized (Molineaux et al., 1986; Readhead and Hood, 1990), disruption of normal relationships between axon and oligodendrocyte may affect other aspects of glial differentiation, including secretion of regulatory factors and expression of cell surface proteins. These differences may be the direct cause of altered neuronal phenotypes in shiverer and transgenic shiverer.

A number of differences exist between demyelinating (Trembler) and dysmyelinating (shiverer) mutants. For example, local effects on the axonal cytoskeleton are more apparent in Trembler, but changes in gene expression are more pronounced in shiverer. This might reflect differences in effects of CNS and PNS myelinating glia on axons. Consistent with this possibility, previous studies showed that neurons react differently to PNS and CNS glial environments (Vidal-Saenz et al., 1987; Schwab and Caroni, 1988). Similarly, CNS- and PNS-myelinated fibers differ in ultra- 


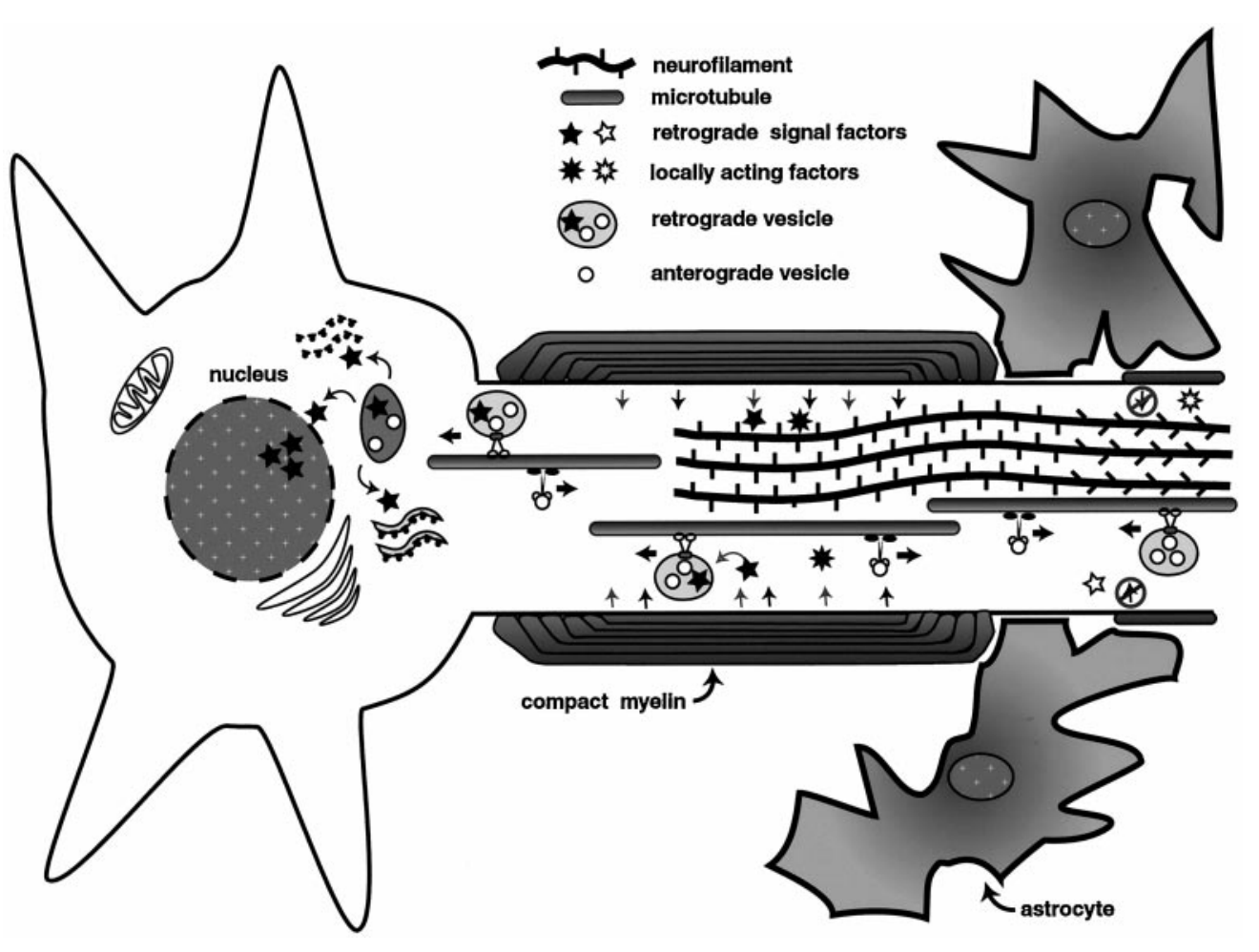

Figure 7. Pathways for compact myelin to affect CNS neuronal differentiation. Although the molecular identity of many components involved in the modulation of neuronal architecture by myelinating oligodendrocytes remains to be determined, essential characteristics of these pathways can be defined. In this diagram, some of these key elements are illustrated schematically. One or more signals is produced by interaction between compact myelin and axon (small arrows). These signals are not produced by simple interaction between an oligodendrocyte process and the axon, such as is seen in shiverer (arrows in circle with bar), but require formation of compact myelin. Signals produced in axon segments surrounded by compact myelin suggest multiple actions. The first may be an action on local factor or factors (eight-pointed star) that changes the net activity of axonal kinases and/or phosphatases, thereby altering the net phosphorylation state of neurofilaments in that segment, much as was seen in Trembler PNS neurons. In this figure, the open symbols represent factors in the absence of myelin, whereas the filled symbols correspond to factors that have been "activated" in the presence of compact myelin. A second action might involve a retrograde acting factor ( filled star) that is committed to retrograde axonal transport and returned to the cell body. At the level of the cell body, this retrograde signal may activate other pathways, directly alter transcription in the nucleus (stars in nucleus), or act at the level of translation in the cell body (stars near polysomes). In the absence of appropriate myelination, axonal signals might fail to be activated (unfilled stars in axon), leading to an altered composition and organization of the axonal cytoskeleton, or may not be returned to the cell body.

structure (Peters et al., 1991) and protein composition (Morell et al., 1994). The extent to which Trembler and shiverer reveal PNS/CNS differences in axon/glia interactions may help characterize the molecular basis for different axonal responses to PNS and CNS environments.

However, phenotypic differences between shiverer and Trembler mutants might account for some differences. In Trembler, compact myelin forms around PNS axons, but does not go to completion. Instead, myelin is resorbed, and Schwann cells continue proliferating. In contrast, shiverer CNS neurons never see compact myelin, whereas $\mathrm{MBP} / \mathrm{MBP}$ transgenic neurons see limiting amounts of compact myelin. Perhaps the myelination level achieved before demyelination in Trembler is sufficient to produce normal expression of neurofilament and tubulin subunits (but not the microtubule-associated protein tau; see Kirkpatrick and Brady, 1994, their Fig. 4), whereas myelin levels in MBP/ MBP transgenics are subthreshold. Support for this idea comes from evidence that mice expressing $50 \%$ or more of wild-type MBP levels have normal myelin sheaths (Shine et al., 1992), suggesting a threshold level of MBP for myelination exists. Analysis of axonal cytoskeletal composition and ultrastructure in mice expressing higher levels of MBP and in mice with a CNS demyelination phenotype should distinguish between these two possibilities.
Differences between MBP/MBP and wild-type axons also indicate that feedback mechanisms must inform neurons about the extent of myelination. Such pathways would be likely to represent mechanisms by which myelin sheath thickness is adjusted to axon caliber (Friede and Miyagishi, 1972). Whereas correlations between axon caliber and myelin sheath thickness is robust and adjustments to sheath thickness associated with changes in axon diameter are well documented, no plausible mechanisms for counting myelin lamellae have been identified. Analysis of mice with different MBP levels may illuminate ways by which myelin sheath thickness is specified.

Functional consequences of altered cytoskeletal composition and organization in $\mathrm{MBP} / \mathrm{MBP}$ and shiverer nerves are not well understood. Partial myelination in $\mathrm{MBP} / \mathrm{MBP}$ mice produces normal life spans and grossly normal behavior under laboratory conditions, but no studies have specifically addressed physiological effects of an altered cytoskeleton. Similarities in fine structure between developing or unmyelinated axons in wild-type mice and mature shiverer axons suggest that aspects of neuronal physiology that change during development might be affected. For example, timing of CNS myelination correlates with the end of critical periods in neuronal development, suggesting that myelination may influence developmental stabilization of synaptic connectivity and neuronal plasticity. One intriguing possibility is that 
critical periods could be extended in myelin deficiency mutants yielding altered or unstable synaptic connectivity. Similarly, inhibition of neurite outgrowth by mature oligodendrocytes that appears during early stages of myelination (Caroni and Schwab, 1989) may be delayed, thereby altering patterns of axonal growth and regeneration in the CNS. Full delineation of changes in CNS neurons associated with deficient compact myelin requires further study.

In summary, CNS myelin deficiencies lead both to local consequences on the axon cytoskeleton (i.e., reduced neurofilament phosphorylation) and to altered gene expression in the cell body (i.e., decreased neurofilament protein). Reduced myelination in $\mathrm{MBP} / \mathrm{MBP}$ nerves converts some parameters to match wild-type completely (transport rates and NFM levels), whereas other parameters match only partially (NFH message), and others were indistinguishable from axons without any myelin (microtubule numbers). Thus, myelination has a profound effect on axonal cytoskeleton properties and composition, but a partial complement of myelin is not sufficient to induce a full response from neurons. Regardless, signals produced during myelination affect differentiation of neurons with large axons and maturation of neuronal function. These data demonstrate that the relationship between neurons and myelinating glia is more complex than previously thought. Understanding the molecular bases of this relationship is critical to understanding how nervous systems can be assembled and maintained.

\section{REFERENCES}

Aguayo A, Attiwell M, Trecarten J, Perkins S, Bray G (1977) Abnormal myelination in transplanted Trembler mouse Schwann cells. Nature 265:73-74.

Brady S (1985) Axonal transport methods and applications. In: Neuromethods, general neurochemical techniques (Boulton A and Baker G, eds), pp 419-476. Clifton, NJ: Humana.

Brady ST (1993) Axonal dynamics and regeneration. In: Neuroregeneration (Gorio A, ed), pp 7-36. New York: Raven.

Campagnoni AT, Macklin WB (1988) Cellular and molecular aspects of myelin protein gene expression. Mol Neurobiol 2:41-89.

Carden MJ, Trojanowski JQ, Schlaepfer WW, Lee VM-Y (1987) Two stage expression of neurofilament polypeptides during rat neurogenesis with early establishment of adult phosphorylation patterns. J Neurosci 7:3489-3504.

Caroni P, Schwab M (1989) Codistribution of neurite growth inhibitors and oligodendrocytes in rat CNS: appearance follows nerve fiber growth and precedes myelination. Dev Biol 136:287-295.

Chernoff GF (1981) Shiverer: an autosomal recessive mutant mouse with myelin deficiency. J Hered 72:128.

Chomczynski P, Sacchi N (1987) Single-step method of RNA isolation by acid guanidinium thiocyanate-phenol-chloroform extraction. Anal Biochem 162:156-159.

Cole JS, Messing A, Trojanowski JQ, Lee VM-Y (1994) Modulation of axon diameter and neurofilaments by hypomyelinating Schwann cells in transgenic mice. J Neurosci 14:6956-6966.

de Waegh SM (1990) The importance of Schwann cell/axon interactions in the local control of neuronal shape and function: the Trembler mouse as an in vivo model. In: PhD thesis in Cell Biology Program, Cell biology, p 202. Dallas: University of Texas Southwestern Medical Center.

de Waegh S, Brady ST (1990) Altered slow axonal transport and regeneration in a myelin deficient mutant mouse: the Trembler mouse as an in vivo model for Schwann cell-axon interactions. J Neurosci 10:1855-1865.

de Waegh SM, Brady ST (1991) Local control of axonal properties: neurofilaments and axonal transport in homologous and heterologous nerve grafts. J Neurosci Res 30:201-212. de Waegh SM, Lee VM-Y, Brady ST (1992) Local modulation of neurofilament phosphorylation, axonal caliber, and slow axonal transport by myelinating Schwann cells. Cell 68:451-463.

Friede RL, Miyagishi T (1972) Adjustment of the myelin sheath to changes in axonal caliber. Anat Rec 17:1-14.

Gould RM, Byrd AL, Barbarese E (1995) The number of SchmidtLanterman incisures is more than doubled in shiverer PNS myelin sheaths. J Neurocytol 24:85-98.

Hoffman P, Griffin J, Gold B, Price D (1985) Slowing of neurofilament transport and the radial growth of developing nerve fibers. J Neurosci 5:2920-2929.

Hoffman P, Koo E, Muma N, Griffin J, Price D (1988) Role of neurofilaments in the control of axonal caliber in myelinated nerve fibers. In: Intrinsic determinants of neuronal forms and functions (Lasek RJ and Black MM, eds), pp 389-402. New York: Alan R. Liss.

Hoffman PM, Lasek RJ, Griffin JW, Price DL (1983) Slowing of the axonal transport of neurofilament protein during development. J Neurosci 3:1694-1700.

Hsieh S-T, Kidd GJ, Crawford TO, Xu Z, Lin W-M, Trapp BD, Clevelan DW, Griffin JW (1994) Regional modulation of neurofilament organization by myelination in normal axons. J Neurosci 14:6392-6401.

Kettenmann H, Ransom BR (1995) Neuroglia, p 1079. New York: Oxford UP.

Kimura M, Inoko H, Katsuki M, Ando A, Sato T, Hirose T, Takashima $\mathrm{H}$, Inayama S, Okano H, Takamatsu K, Mikoshiba K, Tsukuda Y, Watanabe I (1985) Molecular genetic analysis of myelin-deficient mice: shiverer mutant mice show deletion in gene(s) coding for myelin basic protein. J Neurochem 44:692-696.

Kimura M, Sato M, Akatsuka A, Nozawa-Kimura S, Takahashi R, Yokoyama M, Nomura T, Katsuki M (1989) Restoration of myelin formation by a single type of myelin basic protein in transgenic shiverer mice. Proc Natl Acad Sci USA 86:5661-5665.

Kirkpatrick LL, Brady ST (1994) Modulation of the axonal microtubule cytoskeleton by myelinating Schwann cells. J Neurosci 14:7440-7450.

Laskey RA, Mills AD (1975) Quantitative film detection of 3H and 14C in polyacrylamide gels by fluorography. Eur J Biochem 563:335-341.

Lee V, Carden M, Schlaepfer W, Trojanski J (1987) Monoclonal antibodies distinguish several differentially phosphorylated states of the two largest rat neurofilament subunits (NFH and NFM) and demonstrate their existence in the normal nervous system of adult rats. J Neurosci 7:3474-3488.

Lee VM-Y, Carden MJ, Trojanowski JQ (1986) Novel monoclonal antibodies provide evidence for the in situ existence of a nonphosphorylated form of the largest neurofilament subunit. J Neurosci 6:850-858.

Low PA (1976a) Hereditary hypertrophic neuropathy in the Trembler mouse. Part 1. Histological studies: light microscopy. J Neurol Sci 30:327-341.

Low PA (1976b) Hereditary hypertrophic neuropathy in the Trembler mouse. Part 2. Histological studies: electron microscopy. J Neurol Sci 30:343-368.

Low PA, McLeod JG (1975) Hereditary demyelination neuropathy in the Trembler mouse. J Neurol Sci 26:565-574.

Lupski JR, de Oca-Luna RM, Slaugenhaupt S, Pentao L, Guzzetta V, Trask BJ, Saucedo-Cardenas O, Barker DF, Killian JM, Garcia CA, Chakravarti CA, Patel PI (1991) DNA duplication associated with Charcot-Marie-Tooth disease type 1A. Cell 66:219-232.

Mata M, Kupina N, Fink DJ (1992) Phosphorylation-dependent neurofilament epitopes are reduced at the node of Ranvier. J Neurocytol 21:199-210.

Molineaux SM, Engh H, de Ferra F, Hudson L, Lazzarini RA (1986) Recombination within the myelin basic protein gene created the dysmyelinating shiverer mouse mutation. Proc Natl Acad Sci USA 83:7542-7546.

Morell P, Quarles RH, Norton WT (1994) Myelin formation, structure and biochemistry. In: Basic neurochemistry: molecular, cellular, and medical aspects (Siegel GJ, Agranoff BW, Albers RW, and Molinoff PB, eds), pp 117-143. New York: Raven.

Pachter JS, Liem RK (1984) The differential appearance of neurofilament triplet polypeptides in the developing rat optic nerve. Dev Biol 103:200-210.

Peters A, Palay SL, Webster HD (1991) The fine structure of the nervous system: neurons and their supporting cells, Ed 3, New York: Oxford UP.

Popko B, Puckett C, Lai E, Shine HD, Readhead C, Takahashi N, Hunt III SW, Sidman RL, Hood L (1987) Myelin deficient mice: expression 
of myelin basic protein and generation of mice with varying levels of myelin. Cell 48:713-721.

Price R, Paggi P, Lasek R, Katz M (1988) Neurofilaments are spaced randomly in the radial dimension of axons. J Neurcytol 17:55-62.

Raine CS (1984) The morphology of myelin and myelination. In: Myelin (Morrell P, ed), pp 1-41. New York: Plenum.

Readhead C, Hood L (1990) The dysmyelinating mouse mutants shiverer $(s h i)$ and myelin deficient $\left(s h i^{\text {mld }}\right)$. Behav Genet 20:213-234.

Readhead C, Popko B, Takahashi N, Shine HD, Saavedra RA, Sidman RL, Hood L (1987) Expression of a myelin basic protein gene in transgenic shiverer mice: correction of the dysmyelinating phenotype. Cell 48:703-712.

Roach A, Boylan K, Horvath S, Prusiner SB, Hood L (1983) Characterization of cloned cDNA representing rat myelin basic protein: absence of expression in brain of shiverer mutant mice. Cell 34:799-806.

Roach A, Takahashi N, Pravtcheva D, Ruddle F, Hood L (1985) Chromosomal mapping of mouse myelin basic protein gene and structure and transcription of the partially deleted gene in Shiverer mutant mice. Cell 42:149-155.

Rosenbluth J (1980) Peripheral myelin in the mouse mutant Shiverer. J Comp Neurol 193:729-739.

Sanchez I, Hassinger L, Paskevich PA, Shine HD, Nixon RA (1996) Oligodendroglia regulate the regional expansion of axon caliber and local accumulation of neurofilaments during development independently of myelin formation. J Neurosci 16:5095-5105.

Schwab M, Caroni P (1988) Oligodendrocytes and CNS myelin are nonpermissive substrates for neurite growth and fibroblast spreading in vitro. J Neurosci 8:2381-2393.

Shaw G, Weber K (1982) Differential expression of neurofilament triplet proteins in brain development. Nature 298:277-279.

Shine HD, Readhead C, Popko B, Hood L, Sidman RL (1992) Morphometric analysis of normal, mutant, and transgenic CNS: correlation of myelin basic protein expression to myelinogenesis. J Neurochem 58:342-349.

Shrager P, Rubinstein CT (1990) Optical measurement of conduction in single demyelinated axons. J Gen Physiol 95:867-889.

Suter U, Moskow JJ, Welcher AA, Snipes GJ, Sidman RL, Buchberg AM, Shooter EM (1992a) A leucine-to-proline mutation in the putative first transmembrane domain of the 22-kDa peripheral myelin protein in the trembler-J mouse. Proc Natl Acad Sci USA 89:4382-4386.

Suter U, Welcher AA, Ozcelik T, Snipes GJ, Kosaras B, Francke U, Billings-Gagliardi S, Sidman RL, Shooter EM (1992b) Trembler mouse carries a point mutation in a myelin gene. Nature 356:241-243.

Vidal-Saenz M, Bray GM, Villegas-Perez MP, Thanos S, Aguayo AJ (1987) Axonal regeneration and synapse formation in the superior colliculus by retinal ganglion cells in the adult rat. J Neurosci 7:2894-2909.

Virchow R (1846). Über das granulierte ansehen der Wandungen der Gerhirnventrikel. Allg Z Psychiatr 3:242.

Willard M, Simon C (1983) Modulations in neurofilament axonal transport during development of rabbit retinal ganglion cells. Cell 35:551-559. 